\title{
OPETA ROBOTEILLA
}

Markku Leino

First Lego League, markku.o.leino@gmail.com

\section{Robottien historiaa}

Käsillätekeminen ja kokeileminen on erinomainen tapa oppia. Konstruktionismin isä Seymour Papert kehitti opetusrobotteja ja Logo-kieltä jo 1960-luvulta alkaen, ja tämän tutkimuksen tuloksena syntyivät mm. legorobotit MIT:n medialaboratoriossa. Tekemällä oppii, mutta lattialla kulkevan Logo-turtlen kanssa havaittiin käytännön toleranssiongelmia - robotti ei kulje aivan sinne minne se ohjataan. Turtle siirtyi tietokonenäytölle.

Lego-robotit kehittyivät, ja vuonna 1986 julkaistiin ensimmäinen tietokoneella ohjattava Lego-tuote. Kymmenen vuotta myöhemmin julkaistiin keltainen RCX, jonka ohjelmoiminen oli hankalaa. Seuraavat mallit, taas kymmenen vuoden jälkeen julkaistu NXT ja 2009 esitelty hieman muunneltu NXT2 ovat käyttökelpoisuudeltaan jotain aivan muuta.

Uusin legorobotti, vuonna 2013julkaistu EV3, on vielä hieman parannettu versio. Muistia on paljon enemmän ja robotti on tehokkaampi, mutta oleellisia eroja vanhaan NXT:hen ei ole.

\section{Kuinka monta robottia}

Lego-robotit, eli Mindstorms-robotit, ovat melko kalliita, ja hinta helposti rajoittaa niiden käyttöä koulussa opetustarkoituksiin. Kerhon puolella pienempikin määrä robotteja riittää. Robotteja myydään kuluttajaversiona sekä kouluille suunnatuin Education-paketein. Jälkimmäinen on reilusti kalliimpi, mutta suuren osan hinnasta maksaa ohjelmisto, joten ostettaessa useampia hinnasta kannattaa neuvotella. Lisäksi Education-versiossa on hieman erilaiset ja eri määrä osia kuin kuluttajaversiossa, ja säilytysastia on varsin kätevä Legolaatikko pienillä lokerikoilla.

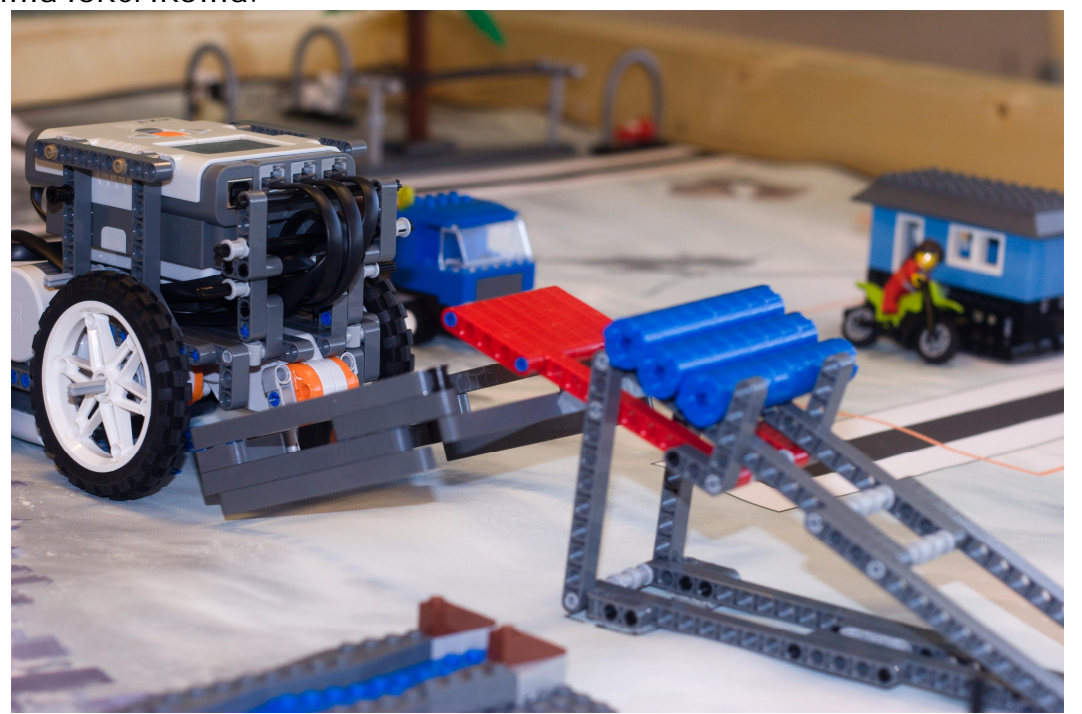

Kuva 1. Hyvin yksinkertainen legorobotti valmiina päästämään tsunamin aallot vapaaksi. 
Itse pidin kerhoa aluksi yhdellä robotilla kuudelle oppilaalle, mutta pian sain toisen robotin. Ikävä kyllä, se ei nopeuttanut eikä juurikaan parantanut robottien kehitystyötä, vaan yhä samat kerholaiset olivat aktiivisimpia, ja toinen robotti lähes käyttämättömänä.

Käytännössä pareittain toimiminen voi olla paras, tai kustannustehokkain tapa toimia. Myös kolme oppilasta robottia kohti saattaa toimia, mutta kolmannen pyörän ongelma saattaa vaikeuttaa ryhmädynamiikkaa.

Monen robotin säilyttäminen ja varastoiminen on myös ongelma. Education-setissä tulee mukana hyvät pinottavat säilytyslaatikot, mutta nekin vaativat tilaa. Varaosia, lisäosia ja laajennuspaketteja kannattaa myös ostaa, jotta rakennussuunnitelmat eivät kariudu osien puutteeseen.

\section{Robotit opetuksessa}

Yläkoulussa robotteja voi soveltaa piirtämiseen ja lattialla kulkemiseen kuten Logo-turtlea, mutta robotiikan integroiminen opetussuunnitelmaan on hankalampaa. Robottien rakentaminen on hidasta, vaikka oppilaat seuraavat valmiita ohjeita. Fysiikkaa ja tietotekniikka ovat selvimmät aineet, joissa robotiikkaa voi soveltaa, mutta esimerkiksi Irlannissa on yhdistetty (alakouluissa) historiaa, äidinkieltä ja musiikkia robottirunoudessa ja -teatterissa. Suomessa Innokas-verkosto yhdistää robotiikan tanssiin, ja järjestää lajissa kilpailujakin.

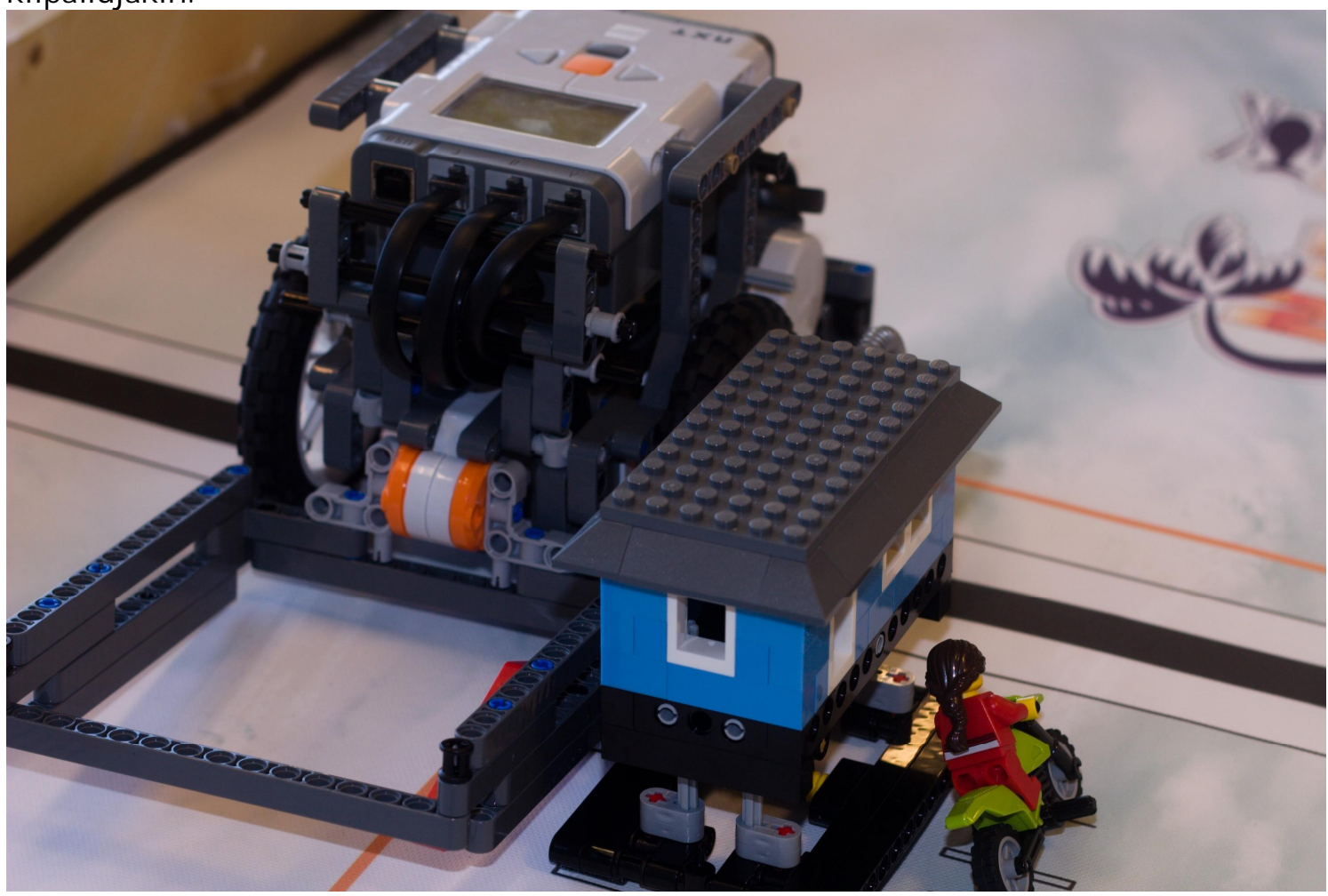

Kuva 2. Legorobotti nostamassa luonnonkatastrofissa hajonnutta taloa takaisin ylös. FLL-kilpailun teemat vaihtelevat vuosittain hyvin laajalla skaalalla vanhusten hoidosta nanoteknologian kautta ruuantuotantoon. 
Matematiikkaa ja elektroniikkaa tai kuvataidetta voi soveltaa roboteilla, mutta ilman järkevää suunnitelmaa se helposti menee keinotekoiseksi yhdistämiseksi.

Erilaisia tapoja soveltaa robotiikkaa on kokeiltu paljon, mutta selkeästi parasta mahdollista tapaa ei ole keksitty. Avoimen laboratoriotyön puitteissa robotit voivat innostaa uusia mielenkiintoisia ratkaisuja vanhoihin, tuttuihin ongelmiin. Ohjattuina tunteina taas vaikeus ja monipuolisuus tuottavat ongelmia.

Kerhona, omana oppiaineena tai atk-tunneilla robotiikka sopii erinomaisesti. Usea yläkoulu on jo teknologiapainotteinen, ja teknologiaopetukseen robotit kuuluvat olennaisena osana. Esimerkiksi tavallisten mekaanisten koneiden kehittäminen ja suunnittelu onnistuu helpolla Lego-palikoilla.

\subsection{Anturit ja servot}

Mindstorms-paketin mukana tulee melko kattava valikoima antureita, esimerkiksi kosketus-, väri-, gyroskooppi- ja ultraäänisensorit. Siihen voi liittää myös kaikki muut Legon valmistamat anturit, ja lisäksi lukemattoman määrän muita antureita. Esimerkiksi Vernierin ja Hitechin anturit saa robottiin kiinni. Moottorit ovat servoja, eli niitä voi käyttää samalla kiertokulman mittaamiseen.

Antureiden ja servojen resoluutio eli tarkkuus on leluluokkaa, mutta taitavalla ohjelmoinnilla ja hyvällä työllä niiden pienet puutteet voidaan kompensoida. Gyroskoopin avulla voi tehdä vaikka Segwayn, eli kahdella rinnan olevalla renkaalla tasapainoilevan kulkijan. Tarkat tulokset toki vaativat hyvän ja monipuolisen ohjelmoinnin ja opettajalta aika paljon tietämystä.

\subsection{Robottien design}

Legoilla rakentaminen on hauskaa. Aluksi Legot toimivat arkkitehtoonisena alustana, sitten lisätään mekaniikkaa. Mekaanisia koneita ja muita ihmeellisiä härpäkkeitä on helppo ja kiva tutkia ja suunnitella Legojen avulla. Vapaa rakentelu tuottaa mitä mielikuvituksellisempia ratkaisuja, jotka kaikki eivät kuitenkaan teknisesti toimi.

Hyvän ja monipuolisen robotin tekeminen on työlästä ja se vaatii hyvin paljon suunnittelua. Esimerksi FIRST Lego League -kisarobottien suunnittelua ja designia varten robotti pitää suunnitellaja rakentaa uudelleen jopa kymmeniä kertoja.

Design ja suunnittelu ovat vaativaa mutta innostavaa työtä. Yksinkertaiseenkin ongelmaan erilaisia ratkaisuvaihtoehtoja on paljon, ja niiden esitteleminen esimerkiksi koulun tai kerhon blogissa voisi olla hyvinkin mielenkiintoista.

\subsection{Ohjelmisto ja ohjelmointi}

Lego-robottien ohjelmointi graafisella ympäristöllä on helppoa, kuin Scratchilla ohjelmoisi. Uusi EV3:n ohjelmointiympäristö on mielestäni huomattavasti parempi, mutta vanhempaa NXT:tä voi ohjelmoida EV3:n softalla. Toki siinä on muutamiajippoja, jotka on mainittu esimerkiksi www.luntti.net/FLL -sivustolla. Ohjelmointi tuo arkkitehtuurin ja mekaniikan lisäksi käyttäytymisen: Lego-vehkeet saadaan käyttäytymään tietyllä tavalla. 
Ohjelmointiympäristö on enilainen kuluttaja- ja kouluversioissa. Kouluohjelmisto on maksullinen ja tavallinen on ilmainen. Minä olen käyttänyt tavallista versiota, vaikka sillä ei pysty piirtämään robottiantureiden mittaamaa dataa suoraan. Toki data voidaan tallentaa robottiin, siirtää tietokoneelle ja piirtää vaikka taulukkolaskenta-ohjelmistolla. Lisäksi kouluversio ohjelmistosta on ulkoasultaan hieman erilainen, eli ei niin tummasävyinen.

Ohjelmointi itsessään on helppoa ja kieli on monipuolinen. Antureiden ulostuloja on helppo käyttää apuna, ja esimerkiksi viivanseuraajarobotti on helppo tehdä. Ohjelmistosta löytyy hyödyllinen Wait- eli odota-lohko, joka odottaa, kunnes jotain tapahtuu. Sen voi ohjelmoida vaikka kulkemaan suoraan ("odota" moottorit käynnissä) kunnes etäisyysanturi näkee esteen $10 \mathrm{~cm}: \mathrm{n}$ etäisyydellä.

Moottorit ovat oikeasti servoja, joten niiden kiertokulma on tiedossa. Moottoreille menevä virta voidaan myös mitata - soveltuu kivasti fysiikan hommiin. Myös kännykällä tai tabletilla voi ohjata EV3:sta radio-ohjattavan tapaan Bluetooth-kanavan yli. iPadille tuli uusi yksinkertainen ohjelmointiympäristö keväällä 2015.

\section{Koulutusta opettajille}

Robottien käyttöönotto ainakin pienessä mittakaavassa, esimerkiksi kerhon puitteissa onnistuu antamalla oppilaille robotit ja antamalla heidän innovoida. Ideoita yksittäisistä rakennelmista ja ajatuksista löytyy netistä todella paljon. Suoraan hakukoneella tai YouTubesta hakemalla löytää ohjeita ja ideoita. Joitain esimerkkejä olen kerännyt osoitteeseen www.luntti.net/FLL/linkkeja.php

Innokas-verkosto järjestää koulutusta eri puolilla Suomea. Niihin kannattaa osallistua ja samalla verkostoitua muihin Lego-opettajiin. Legoilu Suomen kouluissa on vielä melko nuorta, mutta yhdessä toimimalla ja levittämällä hyviä käytänteitä toisillemme voinemme saada suomalaista nuorisoa innostumaan tekniikasta.

Ulkomaankielisiä kirjoja löytyy paljon, mutta suomenkielinen materiaali on vähäistä. Lyhyitä pikaohjeita on www.luntti.net/ FLL -sivustolla, ja Pekka Pihola kirjoittaa suomalaista Lego-robottikirjaa suomalaisen OPS:in mukaan suomalaisille opettajille. Kirja julkaistaan lokakuussa 2015 ilmaiseksi jollain tarkoituksenmukaisella lisenssillä.

\section{$5 \quad$ Kisaillu}

Lego-robotit sopivat konstruktionismin hengessä rakenteluun ja kisailuun. Suomessa suosittuja lajeja ovat RoboCup ja sumorobotteilu. Sumoilu on tyypillistä sumopainia, jossa robotille on koko- ja painoraja. Samaten antureiden ja moottorien määrää on rajoitettu. Sumo on nopeasti käyttöönotettava, esimerkiksi oppitunnilla, ja oppilaat motivoituvat säännöiltään yksinkertaiseen, mutta jännittävään kisaan helpolla.

RoboCup on monipuolisempi kattonimi, jossa kisaillaan tanssissa, jalkapallossa, pelastuksessa, sumossa ja freestylessä. Tanssissa yhdistetään robotiikkaa, musiikkia ja oppilaiden tanssia. Jalkapallossa hyökkääjää saa ohjata, mutta maalivahdin on oltava 
autonominen. Freestylessä saa rakentaa ja innovoida vapaasti - voittaja valitaan yleisöäänestyksellä.

Pelastus on monipuolinen viivanseuranta haasteellisella alustalla, mutta viiva voi olla poikki tai haarautua. Robotin pitää osata kulkea myös ylä- ja alamäkeen ja lopuksi löytää ja siirtää evakuoitava pois vaarasta.

Kilpaileminen on hyvin sosiaalista, sillä siinä tapaa uusia samanhenkisiä kavereita ympäri Suomen tai jopa ympäri maailman. Kisat sopivat myös opettajille ja aloitteleville ryhmille. Kaikki otetaan mukaan.

\subsection{FIRST Lego League -kisa}

FIRST Lego League (FLL) on maailman suurimpia robottikilpailuja, ja siihen osallistuu vuosittain noin 300000 nuorta ympäri maailman. Tänä vuonna Suomesta oli neljäja viime vuonna kuusi nuorta Urjalan yläkoulusta Tallinnassa ja EM-kisoissa Espanjan Pamplonassa kisaamassa. FLL:ssä on vuosittain vaihtuva kenttä ja haasteelliset tehtävät. Tehtäviä on parisenkymmentä, ja niiden säännöt ovat hyvin yksinkertaiset ja motivoivat. Esimerkiksi "Hae silmukka robottikädestä laittamalla kortti aukkoon". Tehtävät ovat haasteellisuudessaan riittävät yliopistoon, mutta kisa on suunniteltu 9-16-vuotiaille.

FLL:ää pelataan pelipöydällä, jonka päivisin nostin luokan seinää vasten ja kerhotuntisin pulpeteille. J oka vuosi tulee uusi alustamatto pöydälle ja uudet tehtävät. Aikaisemmat kilpailut ovat olleet mm. "luonnon raivo", "vanhusten hoito", "nanotekniikka", "ruokatehdas" jne. eli tehtävien skaala on vaihdellut huomattavasti.

Ohjelmoinnin ja designin lisäksi FLL:ssä tuotetaan ja esitetään tieteellinen työ. Ei NASA:kaan lähettänyt Curiosityä Marsiin selvittämättä ensin robotin tulevia olosuhteita. EM-kisoissa maiden parhaat edustajat näyttivät aivan uskomattomia töitä, mutta pienelläkin pärjää ja pääsee alkuun. Oleellista FLL:ssä on hauskanpito, työnteko, joukkuehenki, toisten kunnioittaminen ja ystävällisyys. 


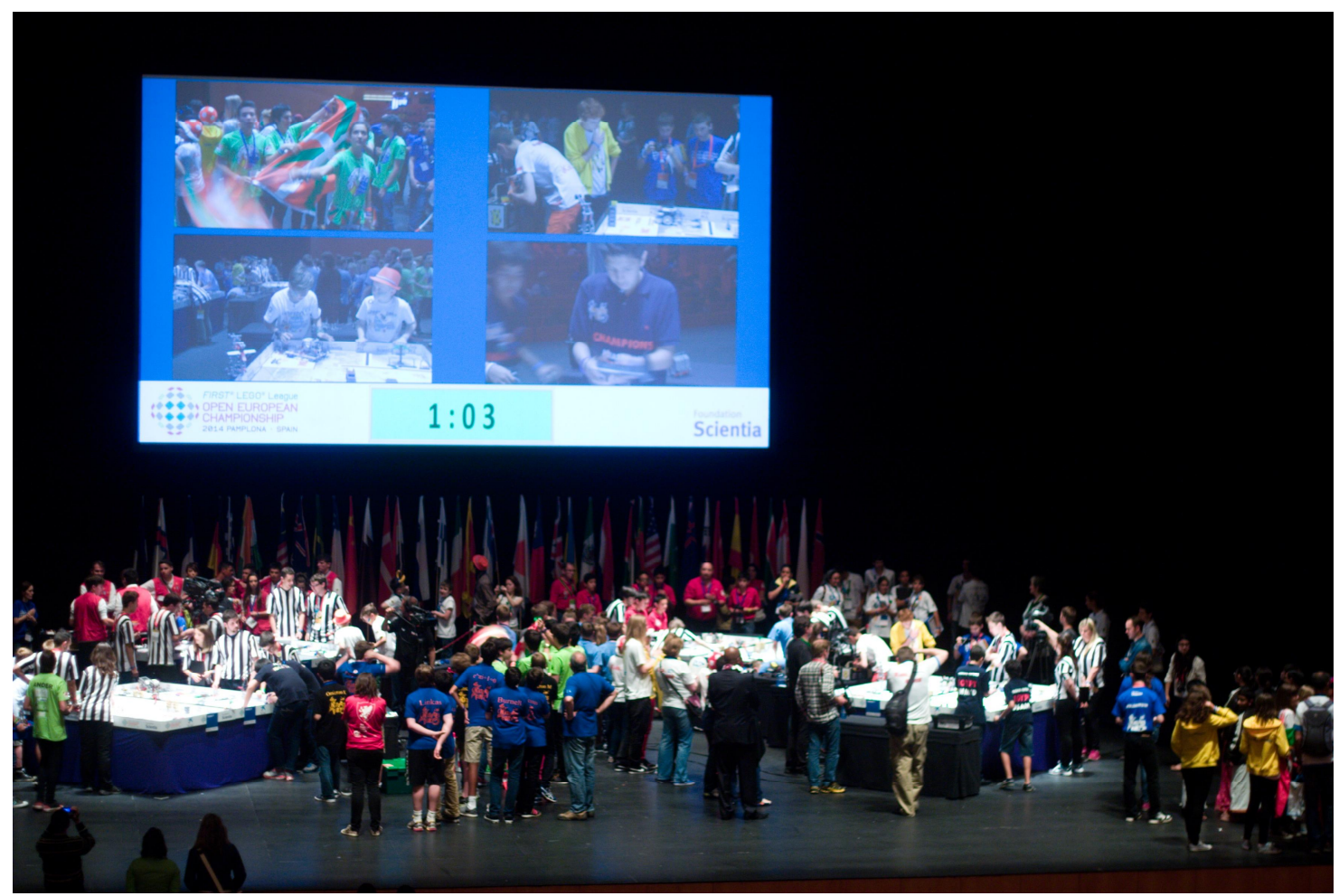

Kuva 2. FLL-kisa on iso tapahtuma. Kuva avoimista EM-kisoista, joissa oli 900 nuorta. Samaan aikaan pelattiin neljällä pöydälläja toiset neljä valmistautuivat. Aikataulu piti koko kisan ajan. Ohjelmointi on vain osa kisaa, sillä myös designiaja tieteellinen työ arvostellaan.

\section{Mitä sitten}

Robotit eivät ole, kuten ei ollut radio tai televisiokaan, opetuksen mullistava menetelmä. Se saattaa toimia joillekin erittäin hyvin, rakentaminen ja käsillä tekeminen yhdistyvät kivasti Lego-roboteissa. Kilpaileminen sopii joillekin, kunhan valmentaja muistaa kisasuorituksen erityislaatuisuuden: vaikka kotona kaikki toimii, niin kisakentällä homma on eri. Robotit saattavat innostaa joitain nuoria luonnontieteiden tai tekniikan pariin, mutta edes tanssivat robotit eivät kaikkiin tehoa. Mahdollisuuksia on paljon, ja niitä voi käyttää alakoulusta yliopistoon. 


\section{Lisätietoa}

FLL:n ydinarvot:

- Olemmejoukkue

- Työskentelemme löytääksemme ratkaisut

- Ohjaajat eivät välttämättä tiedä ratkaisua kaikkiin ongelmiin

- Kunnioitammeystävällistä kilpailuhenkeä

- Löytäminen on tärkeämpää kuin voittaminen

- J aamme löydöksemme muiden kanssa

- Osoitammeystävällistä ammattimaisuutta ja Cooperationia kaikessa

- Pidämme HAUSKAA

Lisätietoa

www.innokas.fi

www.luntti.net/ FLL 